\title{
Early Initiation of Insulin Therapy in Newly Diagnosed Patients with Type 2 Diabetes and Exploring the Legacy Effect-A Single-arm Prospective Observational Study
}

\author{
Shambo S Samajdar ${ }^{1}$, Shatavisa Mukherjee ${ }^{2}$, Santanu K Tripathi ${ }^{3}$, Jyotirmoy Pal ${ }^{4}$, Shashank R Joshi ${ }^{5}$
}

\begin{abstract}
Background: Early insulin has the potential to not only provide glycemic benefit and $\beta$-cell salvage but also reduce microvascular and macrovascular complications. Several reports have shown that the short-term intensive insulin therapy can induce long-term glycemic control in newly diagnosed type 2 diabetes mellitus (T2DM) patients with mild to moderate hyperglycemia. Thus, we hypothesize that a 2-month intensive glycemic control using glargine in newly diagnosed T2DM patients will provide glycemic and legacy benefit.

Objective: To assess whether 2-month treatment with insulin in newly diagnosed T2DM patients (HbA1 c $>9 \%$ ) brings about long-term glycemic control even after stopping insulin after 2 months and also reduction in requirement of other antidiabetic agents.

Method: A prospective single-arm observational study included subjects initiated on insulin, which was stopped after 2 months and lifestyle modification was advised along with oral antidiabetes drugs thereafter. For the initial 2 months, the patients were reviewed weekly and fasting capillary blood glucose was aimed to be maintained between 80 and $130 \mathrm{mg} / \mathrm{dL}$. The included subjects were followed up every 3 months, for a period of 1 year for glycemic parameters.

Results: The study included patients who demonstrated intensive glycemic control with early insulin use. These patients who were followed up over a year in interval of 3 months demonstrated a steep reduction in glycemic indices with time. A steady reduction in mean antidiabetic medications in the subjects was seen over the time period.

Conclusion: Early insulin initiation may result in long-term benefits. Optimum glycemic control in the early stage of diabetes using insulin provides legacy effects and good metabolic memory.

Keywords: Early insulin initiation, Intensive glycemic control, Metabolic memory.

Bengal Physician Journal (2020): 10.5005/jp-journals-10070-7031
\end{abstract}

\section{INTRODUCTION}

Type 2 diabetes mellitus (T2DM) is a disease characterized by progressive loss of mass and function of the $\beta$ cell of the pancreas. Studies have shown that by the time type 2 diabetes develops, more than $70 \%$ of the $\beta$-cell mass is lost and that the loss is initiated at least a decade before the diagnosis of diabetes. ${ }^{1}$ Higher degree of insulin resistance and other $\beta$-cell stress can result in the manifestation of hyperglycemia much earlier along the course of $\beta$-cell loss. Thus, limiting the stress or workload of a dying (but not dead) $\beta$ cell may salvage it and therefore make it functional for a longer period of time. Early initiation of insulin therapy is one of the proposed mechanisms a dying $\beta$ cell may be salvaged, as exogenous insulin helps supplement its function. Thus, early initiation of insulin therapy may halt $\beta$-cell apoptosis. ${ }^{2}$

Insulin is the most effective antihyperglycemic event and landmark studies have shown that early glycemic control delays/ prevents long-term diabetes complications via the "legacy effect" or "metabolic memory." Thus, early insulin has the potential to not only provide glycemic benefit and $\beta$-cell salvage but also reduce microvascular and macrovascular complications. ${ }^{3,4}$ Thus, we hypothesize that a 2-month intensive glycemic control using insulin in newly diagnosed T2DM patients will provide glycemic and legacy benefit. This can result in long-term benefits like later control of diabetes only on lifestyle modification, delayed and later need for antidiabetic agents, and delay or prevention of chronic diabetes complications.
${ }^{1}$ Department of Clinical Pharmacology, School of Tropical Medicine, Kolkata, West Bengal, India

${ }^{2}$ Department of Clinical and Experimental Pharmacology, School of Tropical Medicine, Kolkata, West Bengal, India

${ }^{3}$ Department of Pharmacology, Netaji Subhash Chandra Bose Medical College and Hospital, Patna, Bihar, India

${ }^{4}$ Department of Medicine, RG Kar Medical College and Hospital, Kolkata, West Bengal, India

${ }^{5}$ Indian College of Physicians, Mumbai, Maharashtra, India

Corresponding Author: Shambo S Samajdar, Department of Clinical Pharmacology, School of Tropical Medicine, Kolkata, West Bengal, India, Phone: +91 9831892425, e-mail: shambo_sa2001@yahoo.co.in

How to cite this article: Samajdar SS, Mukherjee S, Tripathi SK, et al. Early Initiation of Insulin Therapy in Newly Diagnosed Patients with Type 2 Diabetes and Exploring the Legacy Effect-A Single-arm Prospective Observational Study. Bengal Physician Journal 2020;7(3):52-54.

Source of support: Nil

Conflict of interest: None

Several researches have conferred that short-term intensive insulin therapy can induce long-term glycemic control in newly diagnosed T2DM patients with mild to moderate hyperglycemia. ${ }^{5-7}$ Another study showed that desired glycemic control was successfully achieved by intensive insulin therapy for 10-14 days in cases of newly diagnosed T2DM patients with severe hyperglycemia.

(0) The Author(s). 2020 Open Access This article is distributed under the terms of the Creative Commons Attribution 4.0 International License (https:// creativecommons.org/licenses/by-nc/4.0/), which permits unrestricted use, distribution, and non-commercial reproduction in any medium, provided you give appropriate credit to the original author(s) and the source, provide a link to the Creative Commons license, and indicate if changes were made. The Creative Commons Public Domain Dedication waiver (http://creativecommons.org/publicdomain/zero/1.0/) applies to the data made available in this article, unless otherwise stated. 
These studies were limited by short duration and in most of these subjects other pharmacological therapy were needed to maintain near-euglycemia. ${ }^{8}$

We therefore hypothesize that early insulin therapy in newly diagnosed T2DM patients will not only improve glycemic parameters but also improve measures of $\beta$-cell function and result in delayed or reduced need of other antidiabetic medications and therefore reduce adverse effects of antidiabetic agents and delay/ decrease/prevent chronic diabetes complications. The present study thus assessed whether 2-month treatment with insulin in newly diagnosed T2DM patients ( $\mathrm{HbA1c}>9 \%$ ) brings about longterm glycemic control even after stopping insulin after 2 months and also reduction in requirement of other antidiabetic agents.

\section{Methodology}

A prospective single-arm observational study was conducted over a period of 1 year. The study included subjects initiated on insulin, which was stopped after 2 months and lifestyle modification was advised along with oral antidiabetes drugs thereafter. For initial 2 months, the patients were reviewed weekly and fasting capillary blood glucose was aimed to be maintained between 80 and $130 \mathrm{mg} / \mathrm{dL}$. The included subjects were followed up every 3 months, for a period of 1 year for parameters like glycated hemoglobin, fasting and postprandial blood glucose, and urine albumin-creatinine ratio (ACR). The need for type of antidiabetes medications (insulin vs oral hypoglycemic agents $[\mathrm{OHA}]$ ) was probed along with number of antidiabetic medications necessitated. Data were entered and analyzed using Statistical Package for Social Sciences (SPSS) version 21 (SPSS Inc., Chicago, Illinois, United States) for Windows.

\section{Results}

The study included 48 patients who demonstrated intensive glycemic control with early insulin use. Mean age of the included subjects was $50.92 \pm 9.45$ years, with sex ratio being 2.66:1 (male:female). Mean body mass index was observed to be $24.38 \pm 3.27 \mathrm{~kg} / \mathrm{m}^{2}$.

Glycemic parameters in terms of mean reduction in glycated hemoglobin and plasma glucose level were noted in interval of 3 months for a year. A steep reduction in glycemic indices was noted (Table 1).

Mean ACR was analyzed for the included subjects, which showed a steep decrease in value within 3 months of treatment (Fig. 1).

Need of antidiabetic medications in the subjects was analyzed, which conferred a steady decrease in mean antidiabetic medications in the subjects over the time period (Figs. 2 and 3).

Table 1: Glycemic parameters

\begin{tabular}{|c|c|c|c|}
\hline & \multirow[b]{2}{*}{$\begin{array}{l}\text { Mean } \mathrm{HbA} 1 \mathrm{c} \\
\text { reduction }\end{array}$} & \multicolumn{2}{|c|}{ Mean plasma glucose reduction } \\
\hline & & $\begin{array}{l}\text { Fasting plasma } \\
\text { glucose }\end{array}$ & $\begin{array}{l}\text { Postprandial } \\
\text { glucose }\end{array}$ \\
\hline Baseline & $13.08 \pm 2.29$ & $283.8 \pm 52.80$ & $404.8 \pm 81.94$ \\
\hline 3 months & $5.92 \pm 0.55$ & $85.4 \pm 13.22$ & $125.2 \pm 15.85$ \\
\hline 6 months & $6.08 \pm 0.37$ & $96.4 \pm 4.77$ & $130.6 \pm 12.16$ \\
\hline 9 months & $6.26 \pm 0.30$ & $97.4 \pm 6.15$ & $129.8 \pm 11.96$ \\
\hline 12 months & $6.22 \pm 0.39$ & $98.5 \pm 5.49$ & $127.3 \pm 15.87$ \\
\hline
\end{tabular}

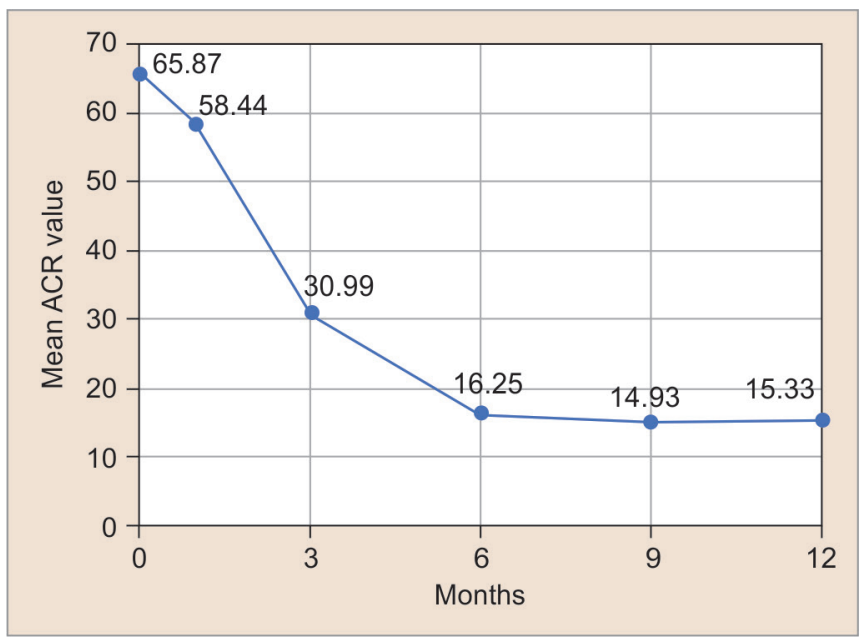

Fig. 1: Mean ACR values in study subjects

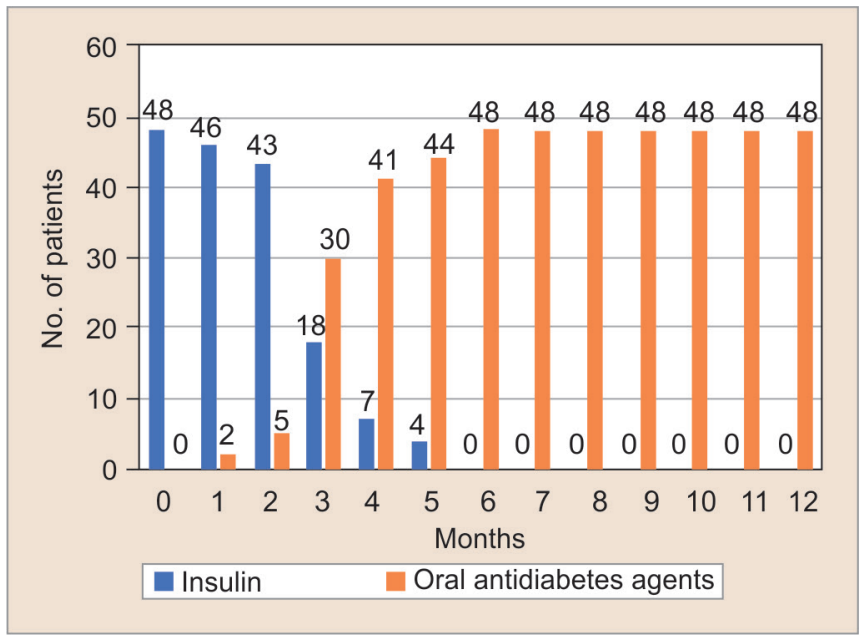

Fig. 2: Need of antidiabetic medications (insulin vs $\mathrm{OHA}$ )

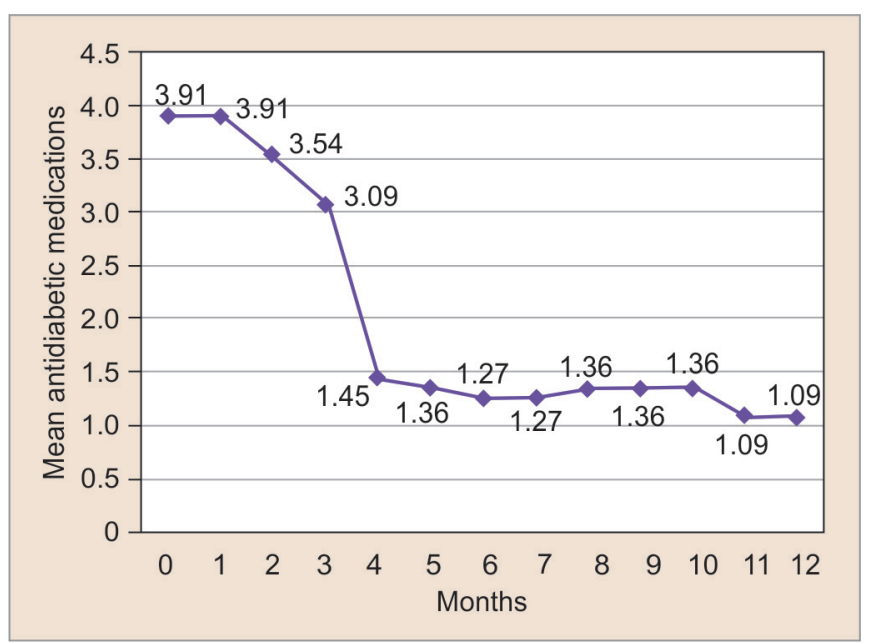

Fig. 3: Need of antidiabetic medications (number of antidiabetic medications) 


\section{Discussion}

Hyperglycemia activates multiple and complex pathogenetically relevant pathways. Inflammatory courses lead to some structural changes like thickening of the basal membrane of microvessels and perivascular fibrosis, resulting in microvascular endpoints in the most susceptible organs, such as renal insufficiency and retinopathy. These structural changes also result in functional impairment and a reduction in blood flow regulation, which subsequently reduces macrovascular endothelial function. This loss of endothelial protection may lead to the subsequent development of atherosclerosis. ${ }^{9-13}$ The structural changes within the microcirculation may account for building up a "metabolic memory." It is important to act before the point of no return. Good glycemic control before this point would give a good longterm outcome as compared to a tight control beyond the point of no return. Institution of appropriate antidiabetes therapy and patients' adherence to such therapy are of paramount importance for the prevention of diabetes-related complications in newly diagnosed cases of T2DM. ${ }^{14,15}$ Studies have shown that compliance with both pharmacotherapy and nonpharmacological measures in diabetes management is relatively poor in some segments of the population.

The recently published guidelines by the American Diabetes Association (ADA) titled "Standards of Medical Care in Diabetes-2020" recommend early introduction of insulin if symptoms of hyperglycemia are present, or when $\mathrm{HbA} 1 \mathrm{C}$ levels $>10 \%$ or blood glucose levels are $\geq 300 \mathrm{mg} / \mathrm{dL}$ or evidence of catabolism like weight loss is present. ${ }^{16}$ The Comprehensive Type 2 Diabetes Management Algorithm (2019) by the American Association of Clinical Endocrinologists also recommends instituting insulin with or without other agents in individuals with entry $\mathrm{HbA} 1 \mathrm{C}>9 \%$ with hyperglycemic symptoms. ${ }^{17}$ In addition to its beneficial effects on cardiovascular risk factors such as cholesterol, triglycerides, and waist-hip ratios, the insulin therapy also appears to partially restore insulin-mediated endothelial function and improve vasodilatation and fibrinolytic profiles. Insulin therapy also has the ability to reverse glucotoxicity, the temporary decline in $\beta$-cell function following chronic exposure to high glucose concentrations. Research suggests that intensive insulin therapy has been shown to significantly improve $\beta$-cell function in patients who have failed maximal doses of oral antidiabetic agents. ${ }^{3}$

The study included patients who demonstrated intensive glycemic control with early insulin use. These patients who were followed up over a year in interval of 3 months demonstrated a steep reduction in glycemic indices with early insulin usage. No signs and symptoms of chronic complications of diabetes, including hospitalization due to diabetes-related morbidities, were observed in the present study subjects. Most of the patients were on metformin only at the end of the 12-month therapy. Decrease in mean ACR value within 3 months of treatment was noted. A steady reduction in mean antidiabetic medications in the subjects was seen over the time period.

However, being a single-arm study, there was no comparator arm, which is a major limitation to this study. Thus, this hypothesis can be further probed with a future randomized controlled trial after proper matching of the baseline parameters.

\section{Conclusion}

Early insulin initiation may result in long-term benefits. Optimum glycemic control in early part of diabetes using insulin provides legacy effects and good metabolic memory.

\section{References}

1. Chen C, Cohrs CM, Stertmann J, et al. Human beta cell mass and function in diabetes: recent advances in knowledge and technologies to understand disease pathogenesis. Mol Metab 2017;6(9):943-957. DOI: 10.1016/j.molmet.2017.06.019.

2. Cerf ME. Beta cell dysfunction and insulin resistance. Front Endocrinol (Lausanne) 2013;4:37. DOI: 10.3389/fendo.2013.00037.

3. Owens DR. Clinical evidence for the earlier initiation of insulin therapy in type 2 diabetes. Diabetes Technol Ther 2013;15(9):776-785. DOI: 10.1089/dia.2013.0081.

4. Silver B, Ramaiya K, Andrew SB, et al. EADSG guidelines: insulin therapy in diabetes. Diabetes Ther 2018;9(2):449-492. DOI: $10.1007 /$ s13300-018-0384-6.

5. Alvarsson M, Sundkvist G, Lager I, et al. Beneficial effects of insulin versus sulphonylurea on insulin secretion and metabolic control in recently diagnosed type 2 diabetic patients. Diabetes Care 2003;26(8):2231-2237. DOI: 10.2337/diacare.26.8.2231.

6. Ryan EA, Imes $S$, Wallace $C$. Short-term intensive insulin therapy in newly diagnosed type 2 diabetes. Diabetes Care 2004;27(5):10281032. DOI: 10.2337/diacare.27.5.1028.

7. Li Y, Xu W, Liao Z, et al. Induction of long-term glycemic control in newly diagnosed type 2 diabetic patients is associated with improvement of $\beta$-cell function. Diabetes Care 2004;27(11):25972602. DOI: 10.2337/diacare.27.11.2597.

8. Chen HS, Wu TE, Jap TS, et al. Beneficial effects of insulin on glycemic control and beta-cell function in newly diagnosed type 2 diabetes with severe hyperglycemia after short-term intensive insulin therapy. Diabetes Care 2008;31(10):1927-1932. DOI: 10.2337/dc08-0075.

9. Jax TW. Metabolic memory: a vascular perspective. Cardiovasc Diabetol 2010;9:51. DOI: 10.1186/1475-2840-9-51.

10. Brownlee M. Biochemistry and molecular cell biology of diabetic complications. Nature 2001;414(6865):813-820. DOI: 10.1038/414813a.

11. Gross ML, Heiss N, Weckbach $M$, et al. ACE-inhibition is superior to endothelin $A$ receptor blockade in preventing abnormal capillary supply and fibrosis of the heart in experimental diabetes. Diabetologia 2004;47(2):316-324. DOI: 10.1007/s00125-003-1309-z.

12. Mauer SM, Steffes MW, Ellis EN, et al. Structural-functional relationships in diabetic nephropathy. J Clin Invest 1984;74(4):11431155. DOI: 10.1172/JCI111523.

13. Mizushige $\mathrm{K}$, Yao L, Noma $\mathrm{T}$, et al. Alteration in left ventricular diastolic filling and accumulation of myocardial collagen at insulinresistant prediabetic stage of a type II diabetic rat model. Circulation 2000;101(8):899-907. DOI: 10.1161/01.cir.101.8.899.

14. Testa R, Bonfigli AR, Prattichizzo F, et al. The "metabolic memory" theory and the early treatment of hyperglycemia in prevention of diabetic complications. Nutrients 2017;9(5):437. DOI: 10.3390/ nu9050437.

15. Berezin A. Metabolic memory phenomenon in diabetes mellitus: achieving and perspectives. Diabetes Metab Syndr 2016;10(2 Suppl. 1):S176-S183. DOI: 10.1016/j.dsx.2016.03.016.

16. Doyle-Delgado K, Chamberlain JJ, Shubrook JH, et al. Pharmacologic approaches to glycemic treatment of type 2 diabetes: synopsis of the 2020 American Diabetes Association's Standards of Medical Care in Diabetes Clinical Guideline. Ann Intern Med 2020;173(10):813-821. DOI: 10.7326/M20-2470.

17. AACE. Glycemic management in type 2 diabetes. Accessed from:https:// pro.aace.com/disease-state-resources/diabetes/depth-information/ glycemic-management-type-2-diabetes [Accessed on March 15, 2021]. 